\title{
Resistivity structure around the hypocentral area of the 1984 Western Nagano Prefecture earthquake in central Japan
}

\author{
Takafumi Kasaya $^{1}$, Naoto Oshiman ${ }^{1}$, Norihiko Sumitomo ${ }^{1 *}$, Makoto Uyeshima ${ }^{2}$, Yoshihisa Iio ${ }^{3 * *}$, and Daijiro Uehara ${ }^{4}$ \\ ${ }^{1}$ Disaster Prevention Research Institute, Kyoto University, Kyoto 611-0011, Japan \\ ${ }^{2}$ Earthquake Research Institute, The University of Tokyo, Tokyo 113-0032, Japan \\ ${ }^{3}$ National Research Institute for Earth Science and Disaster Prevention, Tennodai 3-1, Tsukuba 305-0006, Japan \\ ${ }^{4}$ Sumiko Consultants CO. LTD., Tokyo 166-0021, Japan
}

(Received April 18, 2001; Revised August 14, 2001; Accepted September 2, 2001)

\begin{abstract}
We carried out magnetotelluric measurements in the southeastern region of Mt. Ontake, where the 1984 Western Nagano Prefecture earthquake occurred and earthquake swarms have been observed since 1976. Most of the earthquakes have focal depths shallower than $10 \mathrm{~km}$. The depth of the hypocenters increases towards the west. Our purpose is to delineate the resistivity structures down to the focal depths of the earthquakes, because the resistivity structure is very sensitive to the free water in the crust. The regional strike was estimated as $\mathrm{N} 60^{\circ} \mathrm{E}$. We carried out a two-dimensional analysis over two profiles across the earthquake fault of the 1984 Western Nagano Prefecture earthquake: one is in the low seismicity region of the fault $\left(\mathrm{A}-\mathrm{A}^{\prime}\right)$ and the other, in the high seismicity region $\left(\mathrm{B}-\mathrm{B}^{\prime}\right)$. The resistivity structure along the A- $\mathrm{A}^{\prime}$ profile is reasonably homogeneous and shows a high resistivity of more than $300 \mathrm{ohm} \cdot \mathrm{m}$. The resistivity structure along the B-B' profile has a clear boundary at the center of the profile. This boundary divides the structure along the B-B' profile into two resistivity blocks and its location coincides with that of the earthquake fault. A conductor is detected at depths greater than $8 \mathrm{~km}$ to the northwest of the earthquake fault. The depth to the upper boundary of the conductor coincides with those of the seismic reflectors. This structure seems to be formed by the free water dehydrated from the magma.
\end{abstract}

\section{Introduction}

Earthquake swarm activities began in the southern foot of Mt. Ontake, Central Japan, in August 1976, and the first eruption of Mt. Ontake in history took place in October 1979 (Hori et al., 1982). The 1984 Western Nagano Prefecture earthquake of M6.8 occurred on 14 September 1984 in the region of steady earthquake swarm activities which continued after the 1979 eruption. This earthquake caused heavy damage to the village of Otaki because its hypocenter was located at a shallow depth of $2 \mathrm{~km}$ (Japan Meteorological Agency, 1985). Although ruptures didn't appear on the Earth's surface, the spatial distribution of aftershocks extended in the direction of the strike $\mathrm{N} 70^{\circ} \mathrm{E}$. Yamashina and Tada (1985) showed that the earthquake was caused by a right lateral strike-slip fault whose parameters were $\mathrm{N} 70^{\circ} \mathrm{E}$ in the strike, $74^{\circ} \mathrm{N}$ in dip angle, $24^{\circ}$ in slip angle, $14 \mathrm{~km}$ in length, $2 \mathrm{~km}$ in width, $0.5 \mathrm{~km}$ in depth of the upper margin, and $1.6 \mathrm{~m}$ in slip magnitude, respectively. Shichi et al. (1992) reported that the fault plane of the mainshock ran along a strong gradient belt $\left(\mathrm{N} 40^{\circ} \mathrm{E}\right)$ according to their Bouguer anomaly map.

*Now at the Faculty of Humanities and Sciences, Kobe Gakuin University, Nishiku, Kobe 651-2180, Japan.

**Now at the Earthquake Research Institute, The University of Tokyo, Tokyo 113-0032, Japan.

Copy right (c) The Society of Geomagnetism and Earth, Planetary and Space Sciences (SGEPSS); The Seismological Society of Japan; The Volcanological Society of Japan; The Geodetic Society of Japan; The Japanese Society for Planetary Sciences.
The hypocenters of the aftershocks are concentrated around the area along this estimated earthquake fault and both of it's extremities. The depths to the hypocenters are shallow, normally less than $6 \mathrm{~km}$, at the eastern part of the fault and gradually increase to about $10 \mathrm{~km}$ at the west (Horiuchi et al., 1992). After the subsidence of aftershock activities along the fault, continuous seismic activity was again observed at the eastern side of the fault. The largest aftershock (M6.2) then followed on 15 September at the western side of the hypocentral area of the main shock. Most of the present seismic activities are observed to be located in the same area where the earthquake swarms were observed before the mainshock. Figure 1 shows the epicenters of earthquakes from October to December 1995.

$\mathrm{S}$ wave reflectors are observed in several volcanic regions of Japan. In the present study area, clear S wave reflectors, which were detected by Mizoue and Ishiketa (1988) and Inamori et al. (1992), will be discussed in detail later. The existence of the reflector is interpreted in association with the surface of the magma chamber of Mt. Ontake. The depths of the earthquake swarms were shallower than those of the reflectors, and clear correlation between the depth distribution of the reflectors and hypocentral distribution of the seismic activities is recognized (Mizoue and Ishiketa, 1988; Inamori et al., 1992). On the basis of the relationship between the reflector geometry and the hypocentral distributions, Inamori et al. (1992) pointed out that there is some causal relationship between the reflector and earthquake oc- 


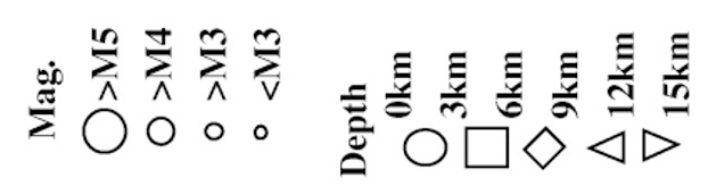

ن.

Latitude

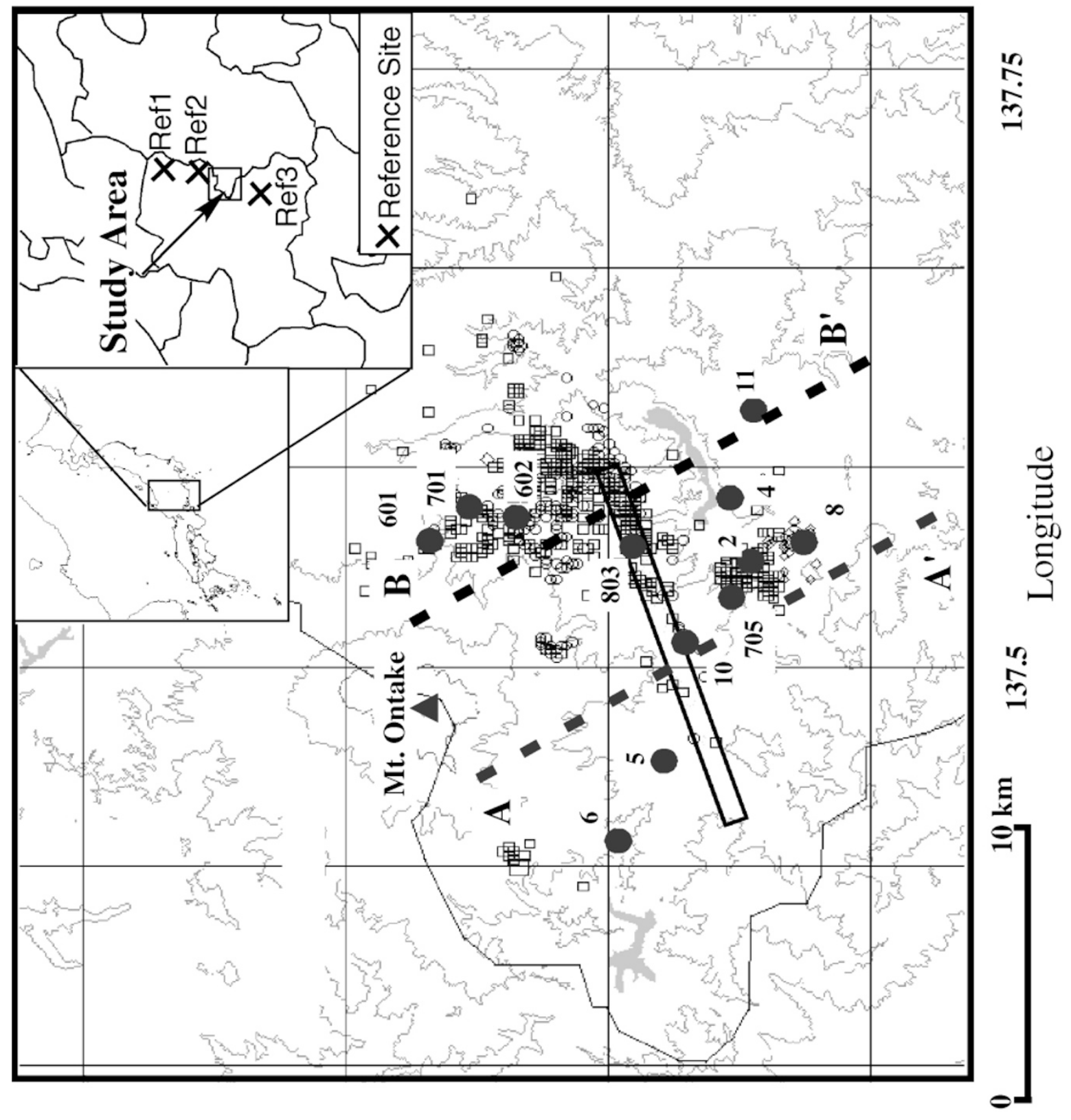

兽这

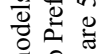

政

忞要

蛋

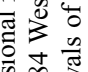

政

夏密

岁吾䛌

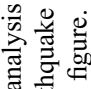

要管

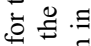

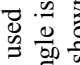

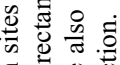

定

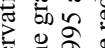

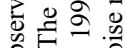

它

5

3를

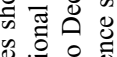

을

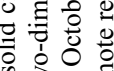

D

$\therefore$ o

年

के छ्ट्य

政

竞

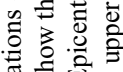

छु

过

के

os कृ ฮ 


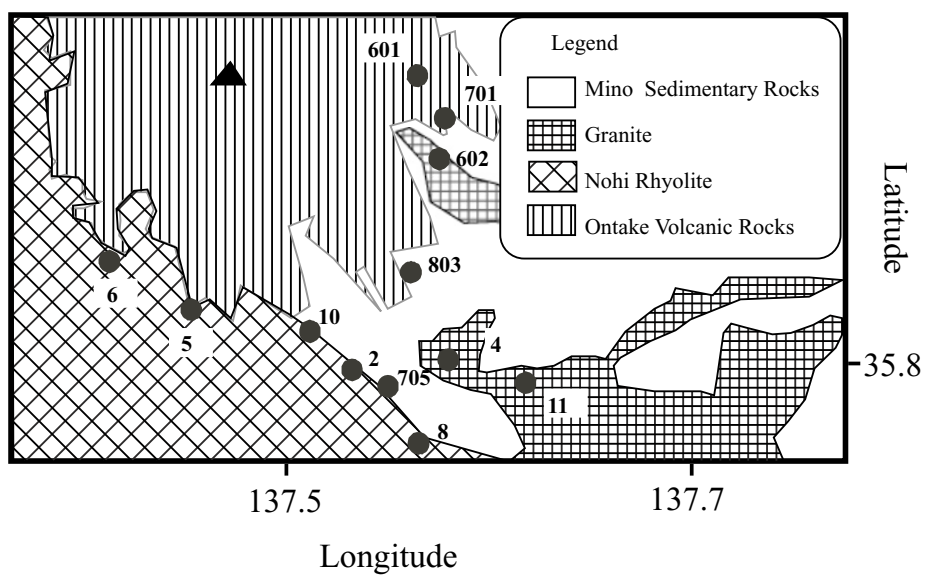

Fig. 2. The simplified geological map by GSJ (1995) around the study area. The survey area is covered with the Mino belt in the Mesozoic or Paleozoic eras, Nohi ryolite, intruded granite, and the andesite outflow from Mt. Ontake. Solid circles indicate the MT survey sites and the solid triangle represents Mt. Ontake.

currence. Such relationships are also reported from the other volcanic areas in Japan (Mizoue and Nakamura, 1982; Horiuchi et al., 1992).

Some seismological investigations suggest that the presence of fluids in the crust play an important role in the process of controlling the seismic activity around the Ontake region (e.g. Tanabe, 1996; Umeda and Ito, 1998; Takeda et al., 1999). The electrical resistivity is a very sensitive parameter for detecting the fluid in the Earth's crust, and it often manifests as a low resistivity zone. Using the MT method, Ogawa et al. (1997) delineated a low resistivity zone corresponding to the reflector determined in the Nikko volcanic area. This was understood to be a result of the trapped free water released from the magma. They pointed out that the seismic activities at shallow depths were due to the water.

The aim of the present paper is to deduce the electrical resistivity of the crust in and the seismicity around the 1984 Western Nagano earthquake region. Two resistivity profiles were selected across the area where the present seismicity is different. The result will be discussed, along with the seismic reflectors and the seismic activity observed here, with emphasis placed on the fluids released from the deeper levels of the crust.

\section{MT Survey and Data Processing}

\subsection{Site location and geological setting}

Magnetotelluric measurements in the frequency range of 384 to $0.0005 \mathrm{~Hz}$ were made at 25 sites around the hypocentral region using the Phoenix V5. Figure 1 shows the location of the sites, of which only those sites denoted as solid circles were used for two-dimensional analysis. The figure also shows the positions of the hypocenters and the fault proposed by Yamashita and Tada (1985). MT measurements were carried out for 2-4 nights at each observation site. A direct current electric railway runs east of the MT survey area and, hence, the noise due to the leakage currents is rather strong. Therefore, we set up observation sites for applying the remote reference processing (Gamble et al., 1979) at a distance of 20-40 km away from the survey area to avoid coherent noise in electric and magnetic records due to the electric railway line. The three crosses in the upper right panel in Fig. 1 show the remote reference sites Ref 1 in Fig. 1 was used for Sites 1 to 11, while Ref 2 and Ref 3 were used for Sites 601, 602 and Sites 701 and 705, respectively. However, the obtained frequency range of reliable impedances was limited to over $0.75 \mathrm{~Hz}$ because the railway operated for almost the entire night.

Figure 2 shows a simplified geological map and the localities of the observation sites. Mt. Ontake, which erupted in 1979, is located in the northwest of the MT survey area. As shown in Fig. 2, the geological formations in this area are divided into three blocks; i.e. Mesozoic sedimentary block, granitic rocks and rhyolite, and andesitic lava and the volcanic outflow of the Cenozoic era. In this area, the marine sedimentary rocks in the Mino belt is the oldest and was formed during the Paleozoic era. The rhyolite was formed by large-scale volcanic activity from the late Cretaceous era to the early Cenozoic era. The granites intruded into the Paleozoic sediments during early Cenozoic times. The basement in this area is composed of the three rock types mentioned above. It is believed that those basements were covered by andesitic rock formed by the volcanic activity of Mt. Ontake.

The resistivities of different rock types detected by borehole resistivity logs, were reported by the New Energy and Industrial Technology Development Organization (NEDO, 1988). They indicate that the electrical resistivities of the andesitic lava, granite, and rhyoritic tuff and sediments are within the ranges of 100-1000, 1000 and 400-500 ohm.m, respectively. According to the measurement results, the metamorphic grade of the andesitic lava and pyroclastic rock is not high. Since the granite and the Mino belt are present over most parts in the study area (Yamada and Kobayashi, 1988; Kimura and Yoshida, 1996), a high resistivity structure is expected over the MT survey area. This is also evident from the predominantly high apparent resistivities (to be discussed later) at high frequencies. So the skin depth expected in the area shown in Fig. 1 is larger for the construction of a two-dimensional model in this study, even if the reliable frequency range is limited over $0.75 \mathrm{~Hz}$. 


\subsection{Strike estimation}

The estimated impedances are often influenced by the local three-dimensional structures. Such an influence may cause some distortion in the image of resistivity structure deduced from two-dimensional analysis. The skew is an index to show the dimensionality of the structure beneath an observation site. The resistivity structures are three-dimensional when the skew is greater than 0.3 (Swift, 1967). We chose 12 sites out of the recorded 25 sites (Fig. 1), where the skew is less than 0.3 , to construct a two-dimensional resistivity structure.

The decomposition technique proposed by Groom and Bailey (1989) is useful for reducing such a local threedimensional effect and for estimating a regional strike. We estimated the strike direction of the two-dimensional structure using the Groom and Bailey decomposition technique. After correcting for the shear and twist, the regional strike directions were obtained at each observation site. Rose diagrams of the principal axis thus obtained at all sites for the frequency ranges of $100-10$ and $10-1 \mathrm{~Hz}$ are shown in Fig. 3. The estimated direction of the strike for 1 to $100 \mathrm{~Hz}$ is almost $\mathrm{N} 30^{\circ} \mathrm{W}$ or $\mathrm{N} 60^{\circ} \mathrm{E}$. The estimated strike direction has an ambiguity of 90 degrees. However, the strike of the earthquake fault of the 1984 Western Nagano Prefecture earthquake is $\mathrm{N} 70^{\circ} \mathrm{E}$, and the strong gradient belt in Bouguer anomaly of the gravity has a trend of its strike along $\mathrm{N} 40^{\circ} \mathrm{E}$ (Shichi et al., 1992). Therefore, we chose the direction of $\mathrm{N} 60^{\circ} \mathrm{E}$ as the regional strike for the two-dimensional resistivity structure in this study. In addition, it seems that the earthquake swarm was mainly active on the eastern side of the survey area where the depths of aftershocks are shallow.
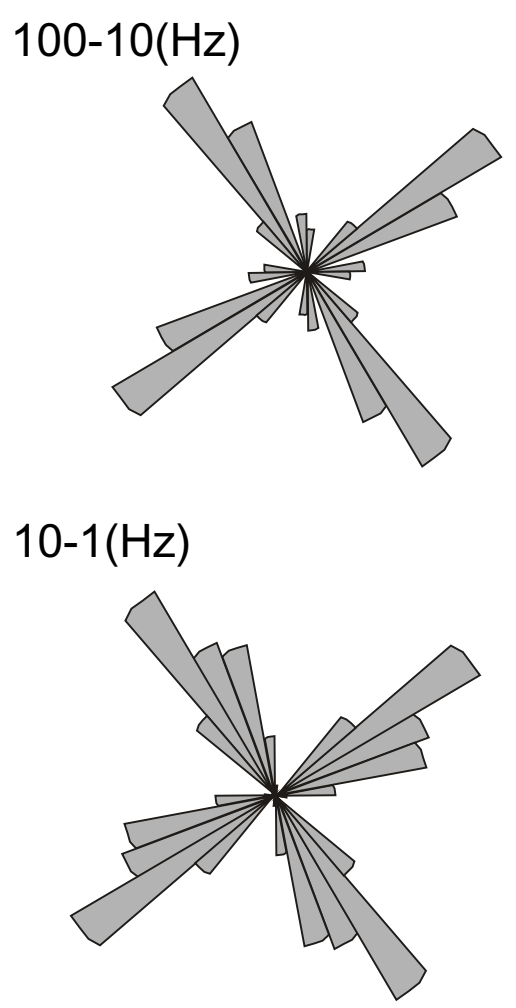

Fig. 3. Rose diagrams of the strike estimates, combined for all the sites, for respective frequency bands.
This suggests that the seismic activities in the eastern area are much different from the western survey area. Therefore, it is very important to compare two-dimensional sections of the resistivity structure across the two areas. Therefore, we chose two two-dimensional sections of $\mathrm{A}-\mathrm{A}^{\prime}$ and ${ }^{\prime} \mathrm{B}-\mathrm{B}^{\prime}$ as shown in Fig. 1.

\subsection{Results of MT soundings}

There is a DC railway line at a distance of $15-25 \mathrm{~km}$ away from the survey area, and it has seriously affected the MT measurements. Some trains were operated at midnight and greatly influenced the data sets. The observed characteristics of such noise effects on the apparent resistivity and phasefrequency curves are (1) the apparent resistivity increases monotonously at a constant rate with decreasing frequency and (2) the phase approaches zero degrees as the sounding frequency is decreased. Takakura et al. (1994) reported electrical train noise and a far remote reference method in detail. We adopted their method to our data. However its result was insufficient. Therefore, our results were obtained by first subjecting the data to the remote reference technique. Next, by selecting difference data segments of the short time intervals recorded during nighttime when relatively fewer trains were operated. By visual inspection, the noisy pair of apparent resistivity and phase curves were removed and not considered for further analysis. Since the apparent resistivities and phases thus obtained could lead to an erroneous estimation of the two-dimensional resistivity structure, we chose the time windows when relatively few trains were operated, mostly during nighttime. Even after this modification in the data collection procedure, the long period measurement showed substantial corruption due to the noise and thus the apparent resistivities and phases could be obtained only within the frequency range $192-0.75 \mathrm{~Hz}$. In view of the high resistivity in the whole survey region, this limited band could also be sufficient to obtain a resistivity structure up to depths of about $10 \mathrm{~km}$.

In order to obtain an overall image of the structure to be delineated along each profile, the pseudosections of the apparent resistivity and phase of TM-mode are drawn (Fig. 4). In this figure, $0 \mathrm{~km}$ on the abscissa indicates the location of the upper edge of the earthquake fault. We used only the TM-mode for constructing our resistivity structure model because the TM-mode is robust against three-dimensional structures (Ting and Hohmann, 1981).

As seen in Fig. 4, the resistivity around $0 \mathrm{~km}$ is relatively lower than the surroundings along both profiles. Along the profile $\mathrm{A}-\mathrm{A}^{\prime}$, the resistivity structure seems to be relatively uniform when compared with the B-B' profile and shows high resistivity as a whole, except around $0 \mathrm{~km}$. On the other hand, along the $\mathrm{B}^{-\mathrm{B}^{\prime}}$ profile, the resistive block is recognized on the eastern side of the profile and corresponds well with the distribution of the granitic rocks in this region. The region of lower resistivity values around $0 \mathrm{~km}$ is very remarkable along this profile and it is also recognizable in the pseudosection of the phase as large phase values.

\section{Two-Dimensional Resistivity Structures 3.1 Two-dimensional model}

We applied a two-dimensional inversion to the TM-mode apparent resistivity and phase data sets, using a scheme with 

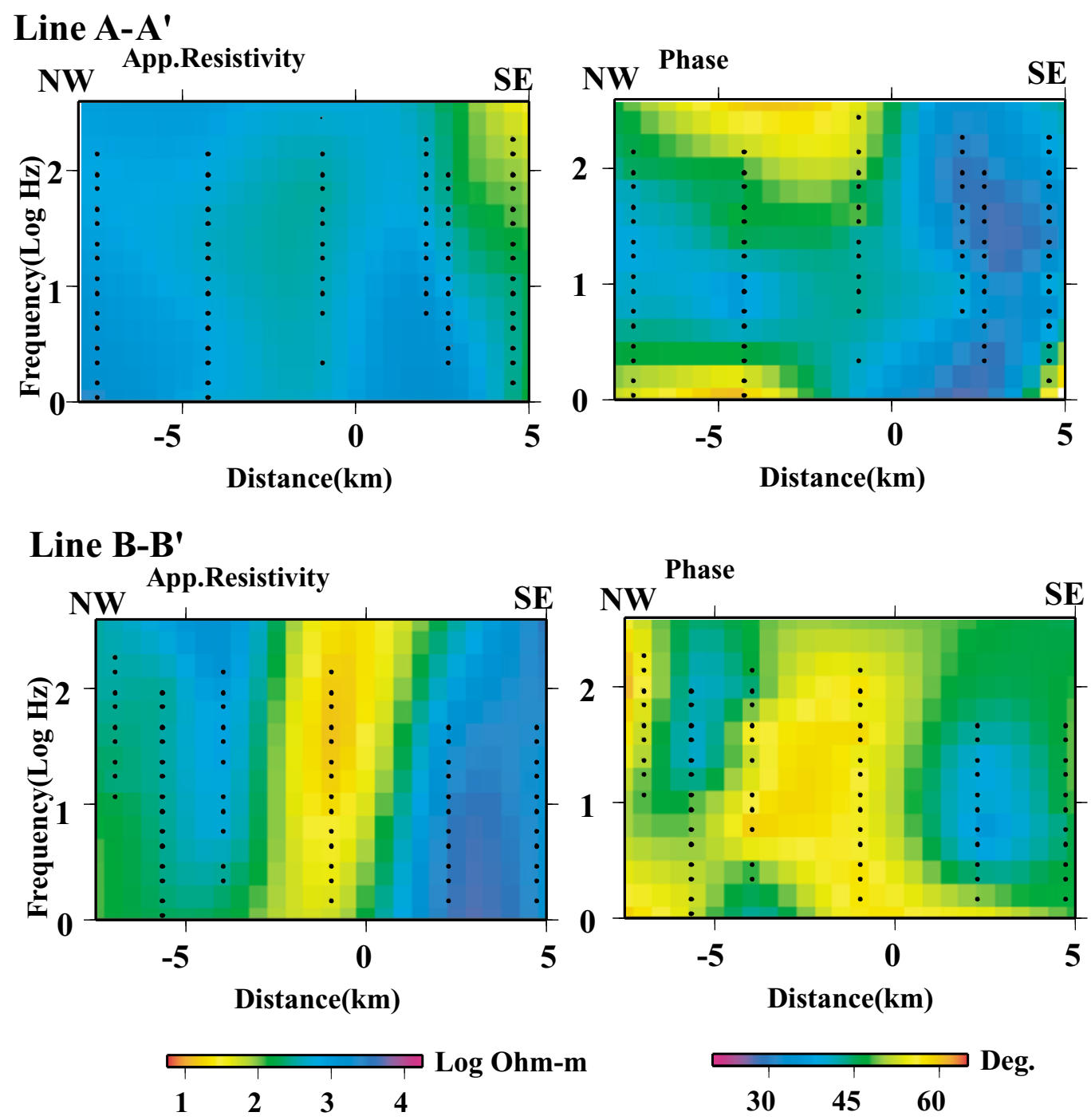

Fig. 4. The pseudosections of apparent resistivity and phase for the TM mode along the A- $\mathrm{A}^{\prime}$ and $\mathrm{B}-\mathrm{B}^{\prime}$ profiles.

smoothness constraint based on Akaike's Bayesian Information Criterion (ABIC) developed by Ogawa and Uchida (1996). The initial model was a uniform half-space with a resistivity of $100 \mathrm{ohm} \cdot \mathrm{m}$ extending on either side of the body by about $300 \mathrm{~km}$ and by $1000 \mathrm{~km}$ in depth, so as to avoid the edge effects due to the abrupt truncation of the resistivity structure. The uniform half-space was divided into $42 \times 57$ whose size increase logarithmically with vertical distance and depth. After 15 iterations, the RMS values became lower than 1.0 for the both profiles.

Figures 5 and 6 show the best fit model obtained for the $\mathrm{A}-\mathrm{A}^{\prime}$ and $\mathrm{B}-\mathrm{B}^{\prime}$ profiles, respectively. Here the hypocenters of earthquakes during the period from October to December in 1995 are also shown. Observed responses and calculated sounding curves deduced from the best fit model are shown in Fig. 7. As seen in Fig. 5, the main portions of the resistivity model along A-A' indicate two high resistivity blocks with resistivities higher than $700 \mathrm{ohm} \cdot \mathrm{m}$. These blocks are separated by a relatively low resistivity region in the central part of the model between sites 10 and 2 . The shallower parts (0-2 km) above the high resistivity blocks have lower resistivity with $300-500 \mathrm{ohm} \cdot \mathrm{m}$. At depths greater than $8 \mathrm{~km}$, the resistivity gradually decreases. On the other hand, the resistivity structure along the B-B' ${ }^{\prime}$ profile shows large variations. Two conductors are detected at shallower $(1-3 \mathrm{~km})$ and deeper portions $(>8 \mathrm{~km})$ in the northwestern half of the model. The resistivity contrast between the high resistivity block to the southeast of Site 803 and the low resistivity block to the northwest, corresponds to the location of the fault associated with the 1984 Western Nagano Prefecture earthquake (Yamashina and Tada, 1985).

The seismic reflectors observed by Inamori et al. (1992) are in the depths range from 7 to $14 \mathrm{~km}$ beneath the northwestern side of both profiles. Inamori et al. (1992) show that the spatial distribution of the reflectors along an E-W section has two branch surfaces: one is steeply dipping towards the east and the other towards the west with a smaller dip angle. The depths of the reflectors on the former surface are about $14 \mathrm{~km}$ (lower S-wave reflector in Fig. 12(b)) on the B-B' profile, while those of the reflectors on the latter surface are about 8-11 km (upper S-wave reflector in Fig. 12(b)). The shallow $\mathrm{S}$ wave reflectors correspond to the top layer of the bottom conductor along the northwestern half of the B-B' profile. The short wavelength negative gravity anomaly is 


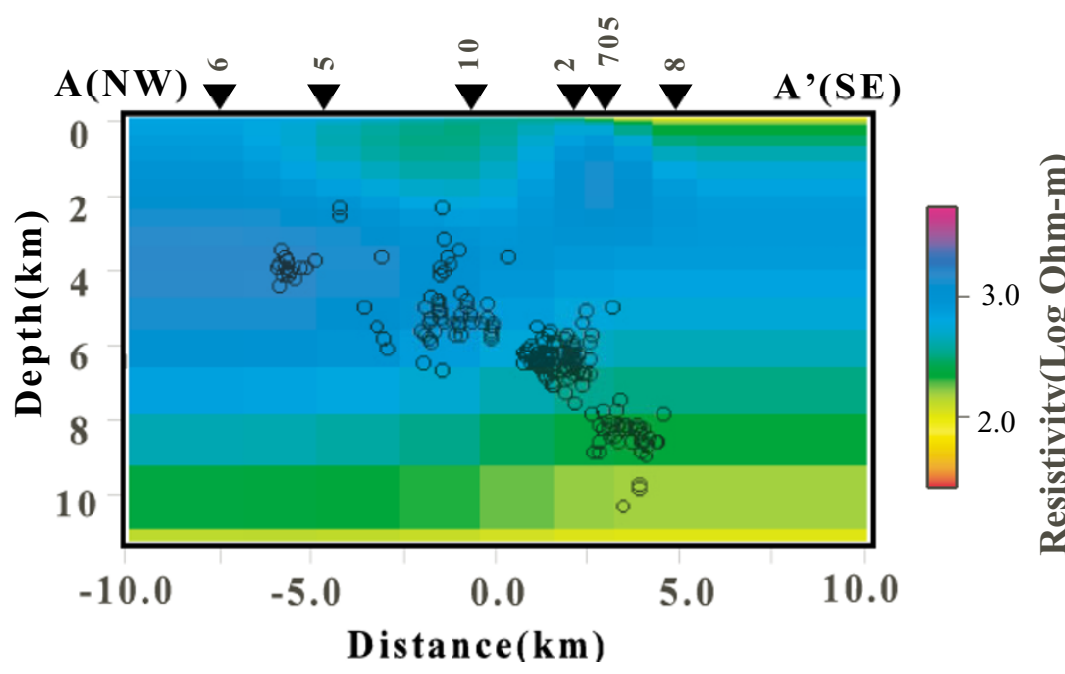

Fig. 5. Resistivity model along the A- $\mathrm{A}^{\prime}$ profile deduced from $2 \mathrm{D}$ ABIC inversion. Triangles represent the locations of the observation sites. Circles represent hypocenters of earthquakes during the period from October to December 1995.

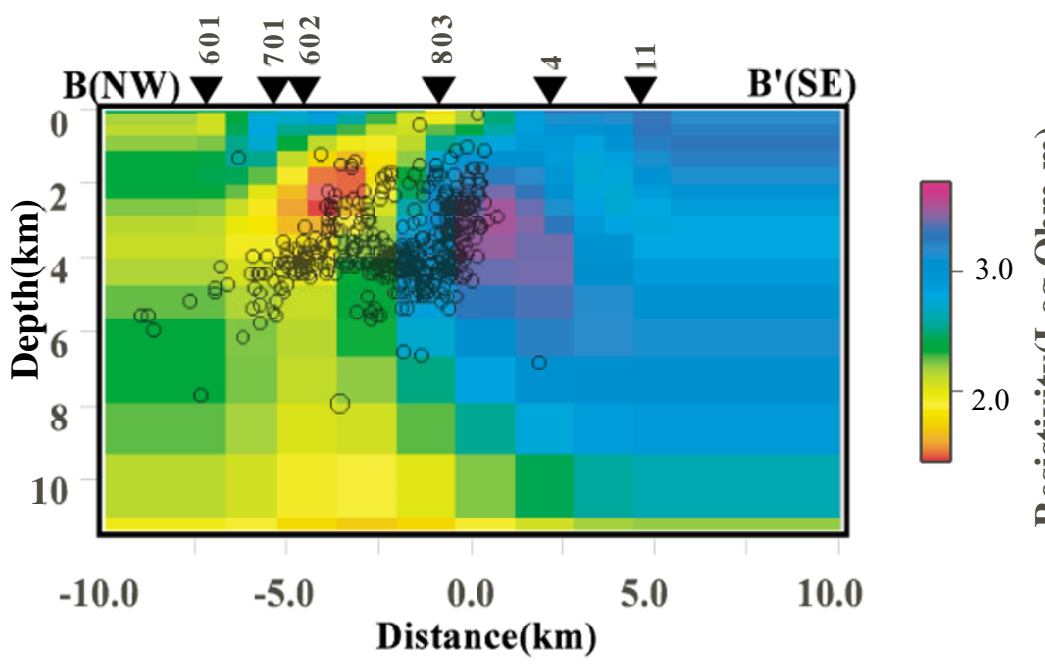

Fig. 6. Resistivity model along the B-B' profile deduced from $2 \mathrm{D}$ ABIC inversion. Reverse triangles represent the observation sites. Circles show the distribution of hypocenters during the period from October to December 1995.

distributed within a narrow area along the earthquake fault around the $\mathrm{A}-\mathrm{A}^{\prime}$ profile and extends toward the northeastern side around the B-B' profile line (see figure 8 of Shichi et al., 1992).

As mentioned in the previous section, the major geological features in this region consist of the Mino belt, Nohi ryolitic, granitic and intruded rocks, and Ontake volcanic rocks (Fig. 2). The survey sites in the northwestern part of the A-A' profile are located over the Nohi ryolite area. It is thought that the basement in this area consists of the Mino belt, ryolite and granite (Yamada and Kobayashi, 1988). Hence, the resistive block in the northwestern part of the A- $\mathrm{A}^{\prime}$ profile can be interpreted as being due to the ryolite. The resistivities deduced by the inversion model is in good correspondence with the electrical logging results (NEDO, 1988). The high resistive body in the southeastern side of the B-B' profile, may be due to either ryolite or granites. The low resistivies at shallow depths is attributed to Mt. Ontake volcanic rocks and outflows. As already mentioned above, the model structures along the B-B' profile is clearly divided into two resistivity blocks. The low resistivity block to the northwestern side is located in the sedimentary sequences of the Mino belt. However, no information is available on the exact resistivity value for each geologic unit.

\subsection{Sensitivity check}

After obtaining a two-dimensional resistivity model, we carried out some sensitivity checks to test some of the significant features along B-B' profile, because we wanted to make a comparison between the model structures and the hypocentral distribution of seismic activities which was very high in this area. Sensitivity checks were done by changing the resistivity of the blocks (a) and (c) in Fig. 8, and by mov- 

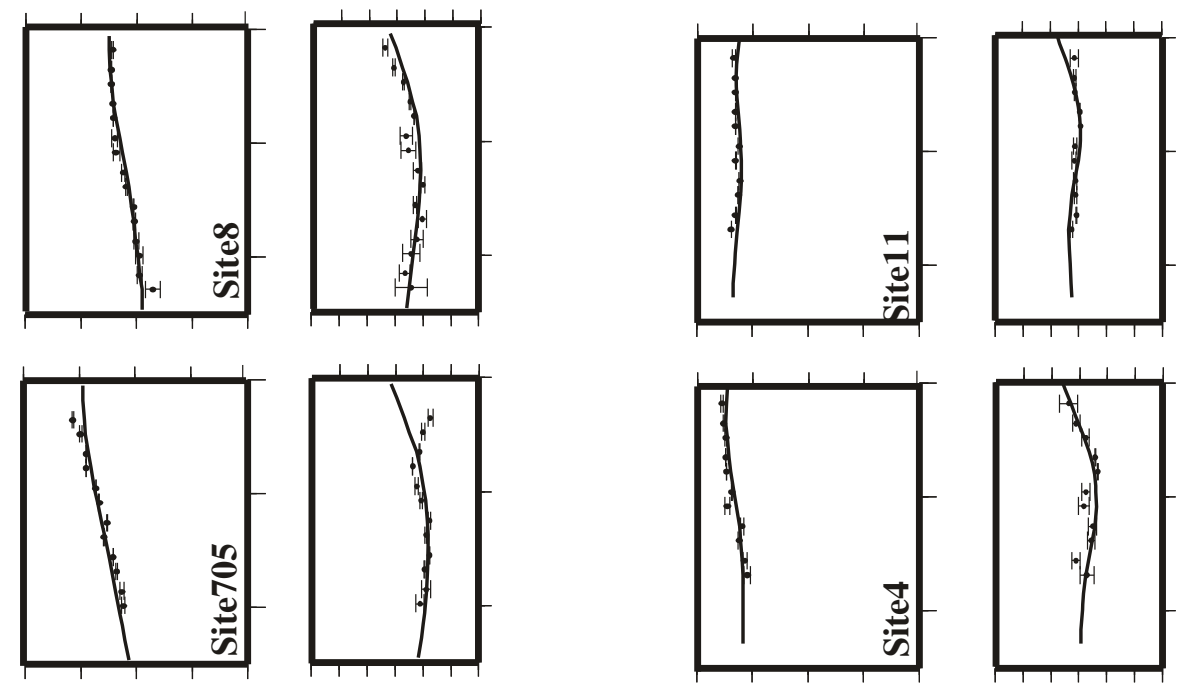

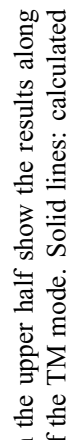
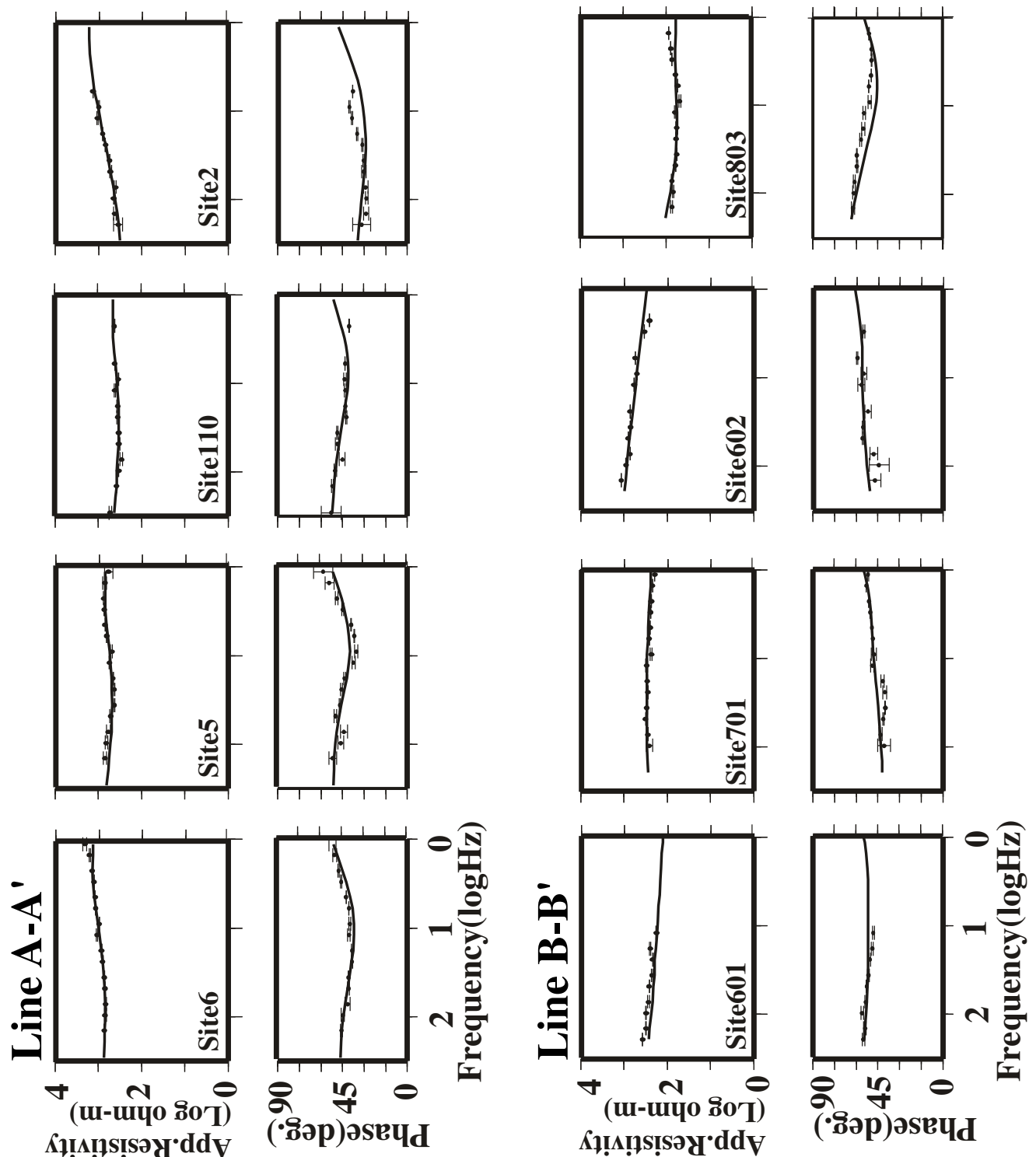

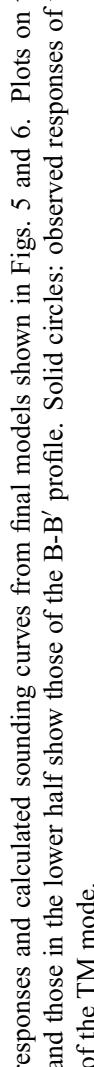

उ 율

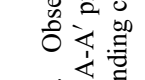

isj 


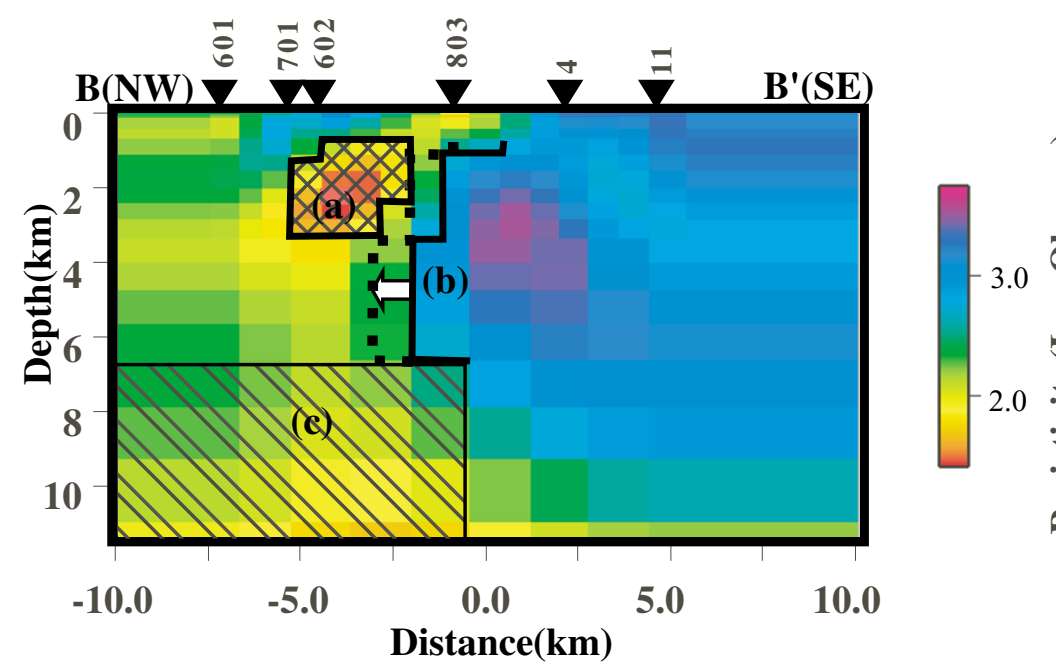

Fig. 8. Modified model to carry out some sensitivity checks. (a) shows the modified resistivity blocks inside which the average resistivity (300 ohm.m) on the northwestern side of the B-B' ${ }^{\prime}$ profile is used. (b) shows that the resistivity boundary was extended laterally toward the northwest, denoted by a dashed line. (c) shows the modified resistivity block in which the resistivity is assumed to be an average value (700 ohm $\mathrm{m})$ at the same depth on the southeastern side of the $\mathrm{B}-\mathrm{B}^{\prime}$ profile.
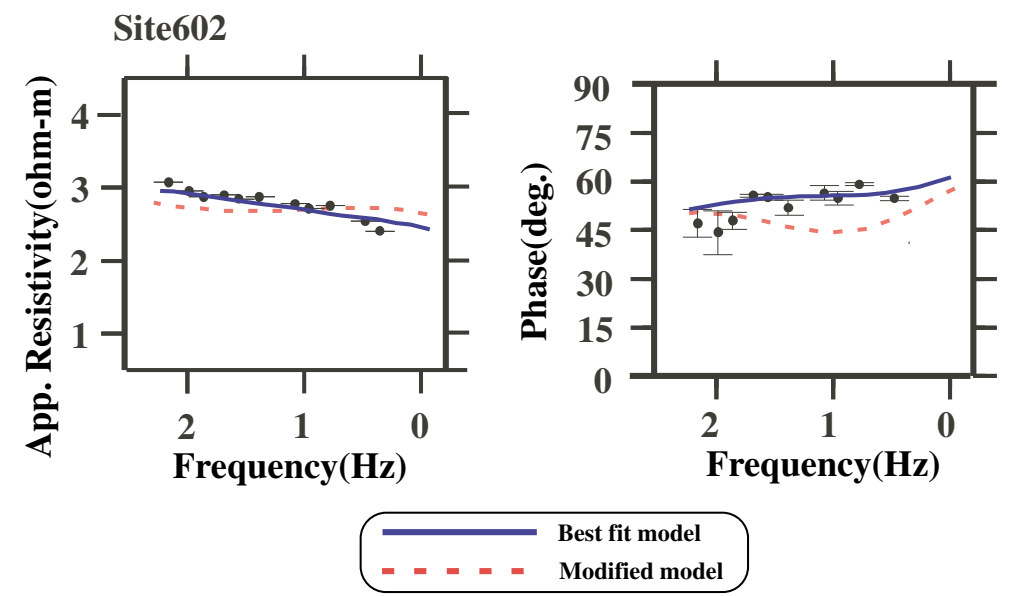

Fig. 9. The calculated sounding curves at Site 602 from the modified model (a) in Fig. 8. The solid line shows the sounding curves calculated from the original model shown in Fig. 6, while the dashed line shows those of modified model (a) shown in Fig. 8, respectively. Solid circles indicate observed responses.

ing the boundary of the block (b) in Fig. 8.

3.2.1 A conductor in the B-B' $\mathbf{B}^{\prime}$ profile As already pointed out in the previous section, a very low resistivity region is delineated at a depth of about $2 \mathrm{~km}$ at the northwestern side of the model along the B-B' profile. We carried out an evaluation of the conductor. We calculated the sounding curves for a model in which the inside of block (a) was assumed to be $300 \mathrm{ohm} \cdot \mathrm{m}$ which is an average value of the resistivity at the outside of block (a) in Fig. 8. The sounding curves for site 602 , which is in close proximity to block (a) are shown in Fig. 9. The solid line shows the response of the model to the inversion shown in Fig. 6, while the dashed line shows that of the modified model. According to the sounding curves shown in Fig. 9, a model without a conductor inside block (a) is not able to explain the observed responses. In particular, the discrepancy between the observed and calculated responses of the phase shows a remarkable change.
3.2.2 A resistive block in the $\mathbf{B}^{-} \mathbf{B}^{\prime}$ profile Figure 10 shows the sounding curves for Sites 4 and 803 calculated from the modified model in which block (b) extends towards the northwest, denoted by dashed line as shown in Fig. 8. In this model, the discrepancy between the two sounding curves for each model is very large and it is difficult to explain the observed responses using the modified model. Thus, we claim here that the left boundary of the high resistive block almost corresponds to the earthquake fault plane.

\subsubsection{A conductor in the bottom of the B-B' ${ }^{\prime}$ profile} We next check the sensitivity of the low resistivity block (c) shown in Fig. 8. The purpose of this sensitivity check is to discover whether the deeper region is conductive or not. Iio et al. (2000) have already proposed that this region is highly resistive. Figure 11 shows the response curves at Sites 4 and 803 calculated from the modified model in which the resistivity in block (c) in Fig. 8 is assumed to 

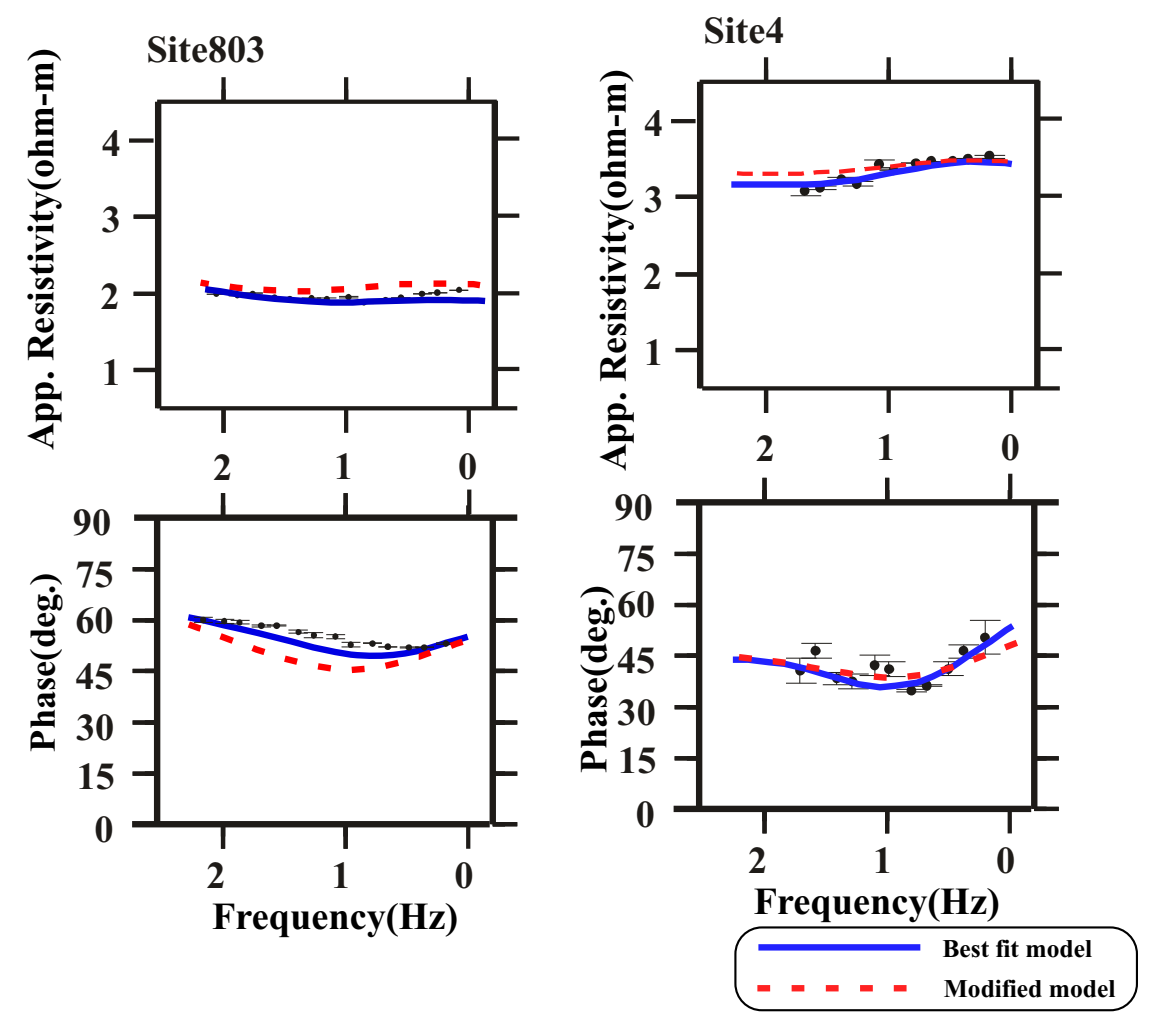

Fig. 10. The calculated sounding curves at Site 4 from the modified model (b) in Fig. 8. The solid line shows the sounding curves calculated from the original model shown in Fig. 6, while the dashed line shows those of the modified model shown in (b) of Fig. 8, respectively. Solid circles indicate observed responses.
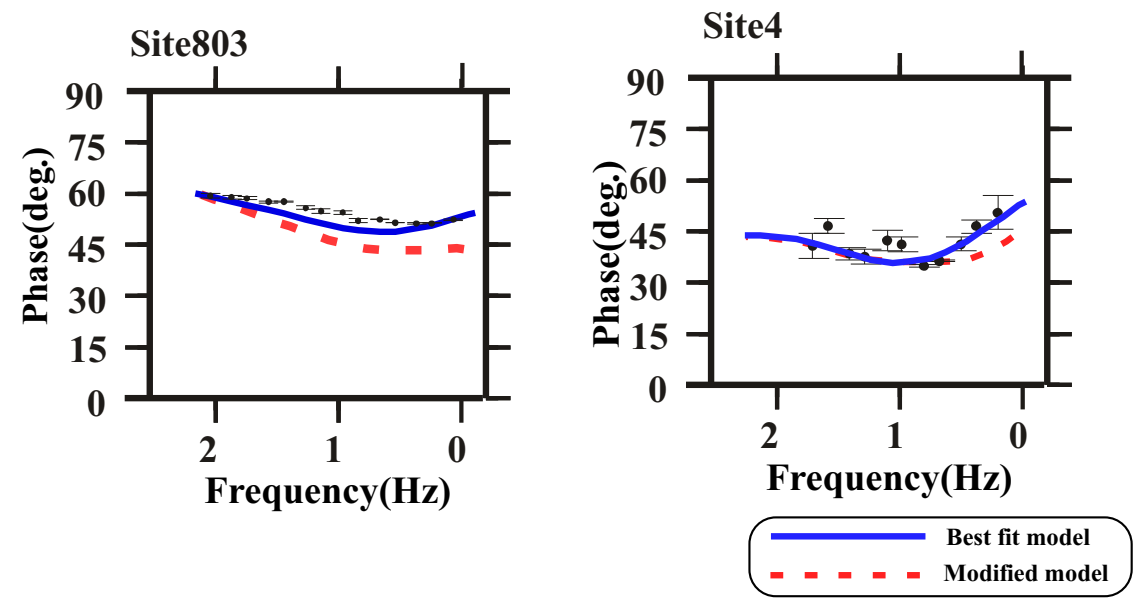

Fig. 11. The calculated sounding curves at Site 4 from the modified model (c) in Fig. 8. The solid line shows the sounding curves calculated from the original model shown in Fig. 6, while the dashed line show those of the modified model (c) shown in Fig. 8, respectively. Solid circles indicate observed responses.

be $1000 \mathrm{ohm} \cdot \mathrm{m}$. Each phase response curve deduced from the modified model (c) disagrees with the observed curve at longer periods. Therefore, the conductor in the bottom of the $\mathrm{B}-\mathrm{B}^{\prime}$ profile is necessary to explain the observed response at longer periods. This is inconsistent with the model of Iio et al. (2000), where a very resistive basement is inferred beneath this region. This discrepancy is caused due to the insufficient removal of the DC train noise in the data of Iio et al. (2000). We point out here again that the depth of the upper boundary of this conductor matches the depth of the upper reflector, as shown in Fig. 12(b).

\section{Discussion}

In this paper, good correlations were found between seismic information and the resistivity structures. Figures 12(a) and (b) show interpretations based upon the two final twodimensional resistivity models along both profiles together with the seismic information. The resistive blocks (R1, R2 


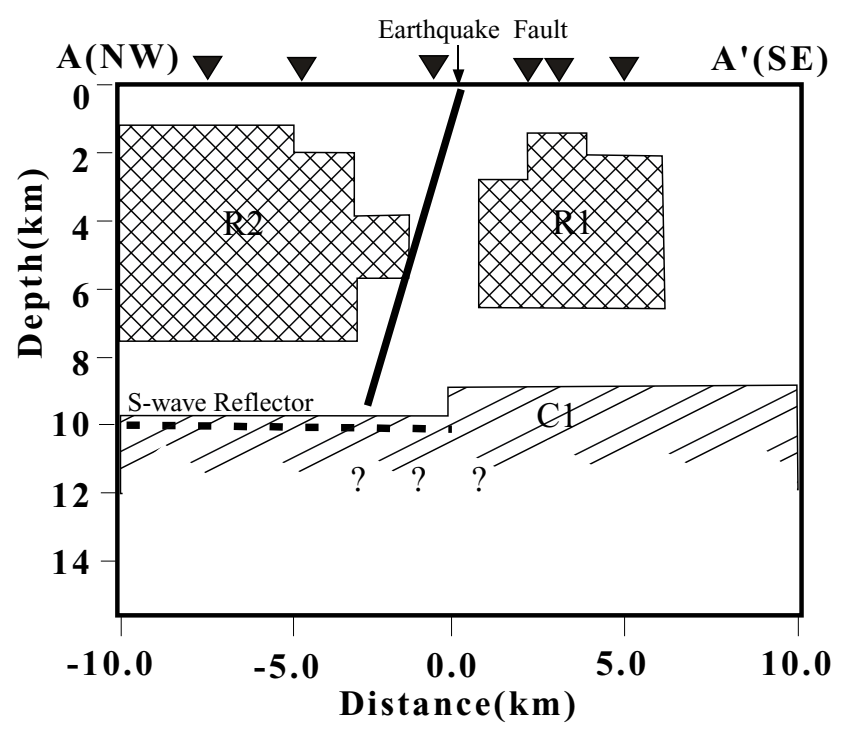

(a)

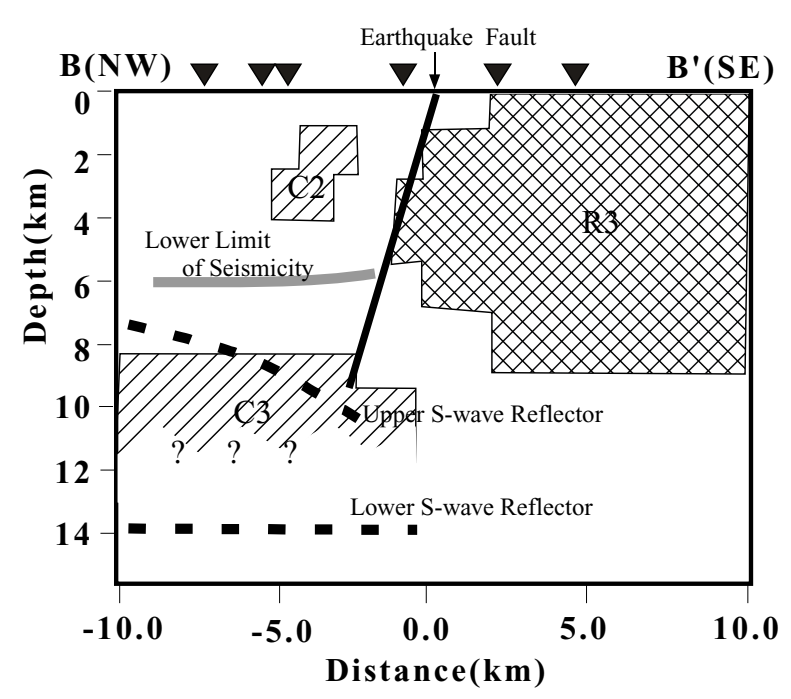

(b)

Fig. 12. Simplified resistivity structure and seismic information (a) along the A-A' profile, and (b) along the B-B' profile.

and R3) imply granite or ryolite. In particular, the shallow northwestern part corresponds to the Mino belt from the logging data. We found that the resistivity boundary coincides with the fault plane and that the fault is underlain by a conductor.

As shown in Figs. 12(a) and (b), the seismic reflectors are located almost along one surface at a depth of $10 \mathrm{~km}$ beneath the A-A' profile, while being distributed along two surfaces at depths of 14 and $8-11 \mathrm{~km}$ beneath the B-B' profile. Iio et al. (2000) also obtained a resistivity structure inferred from MT and CSAMT surveys along the NS profile, which passed through almost the same place at the center of the B-B' profile (see figure 10 in Iio et al., 2000). According to their result, the region deeper than the cutoff depth of the seismicity shows a very high resistivity of about $1000 \mathrm{ohm} \cdot \mathrm{m}$. They could not find low resistive regions corresponding to the existence of the reflectors. However, as shown in the pre- vious section, the bottom of the B-B' profile must be of low resistivity according to the results of the sensitivity check of block (c). The depth of the upper boundary of the low resistive block in our final model coincides with that of the seismic reflectors. The discrepancy between the deeper resistivity structure of Iio et al. (2000) and that reported in this study may be attributed to the effect of noise due to leaking currents from the electric railway. They could not easily avoid the noise effect during longer periods in their analyses.

Inamori et al. (1992) and Mizoue and Ishiketa (1988) pointed out the existence of reflectors on the top of the magmatic body. However, the resistivity of the conductor can be explained not only by the magmatic body but also by the existence of the free water. The relations between $\mathrm{S}$ wave reflectors and the resistivity structure were discussed by Ogawa et al. (1997) for the case of the Nikko area based 
on the results of their wide-band MT survey. They found that a conductive body at a depth of $8 \mathrm{~km}$ overlapped with the location of the seismic reflector, and that a conductive body overlain with a resistive block, could be interpreted as an intruded volcanic rock. They concluded that the low resistivity body could be a result of the trapped free water released from deeper levels, and that it governs the shallow seismic activities. Fuji-ta et al. (1997) also found that the upper boundary of a low resistive region coincided with locations of seismic reflectors at depths of $12-25 \mathrm{~km}$ in the Kii peninsula, in the southwest Japan forearc. They concluded that the presence of a trapped free water zone implies a geotherm of $400^{\circ} \mathrm{C}$. Gupta et al. (1996) described the correlation between the resistivity structure and the cutoff depth of the earthquakes around the hypocentral area of the 1993 Latur earthquake in India. They found a low resistivity layer at the $7-10 \mathrm{~km}$ depth and believed that the low resistivity at that depth may be due to the presence of high conductive fluid. Therefore, the cutoff depth around the Latur earthquake region becomes about 5-6 $\mathrm{km}$. They concluded that the existence of a conductive layer enhances the stress concentration in the uppermost brittle part above $6 \mathrm{~km}$.

Next, we discuss the relationship between the resistivity structure and seismicity. Though the seismic activity was not so high along the $\mathrm{A}-\mathrm{A}^{\prime}$ profile, there are some clustering activities at depths of $6-8 \mathrm{~km}$ and about $2.5-5 \mathrm{~km}$ southeast from the center of the model. We should note that these depths correspond to the bottom of the high resistive body, R1 in Fig. 12(a). A cluster of seismic activity is also detected at depths from 2 to $6 \mathrm{~km}$ in the center of this profile. The resistivity in the clustering area is lower than that of the surroundings, including the earthquake fault. Most of the aftershocks of the 1984 Western Nagano Prefecture earthquake occurred in this area. The seismicity along the B-B' profile seems very high and the hypocenters are distributed at depths of $0-5 \mathrm{~km}$ in the conductive block in the northwestern half of the profile.

Takeda et al. (1999) estimated the crack density and the degree of water saturation from the $V_{p} / V_{s}$ ratio in the crust up to a depth of $4 \mathrm{~km}$, and discussed the possibility of high seismic activity in the Ontake region. They found that the earthquakes occurred in the region where the degree of saturation was low and that the area of high saturation was surrounded by a lower saturated area. They concluded that the main cause of earthquakes was water flowing into the area of low saturation from the area of higher saturation. Tanabe (1996) revealed that the depth of the seismic reflectors before the occurrence of the 1984 western Nagano Prefecture earthquake was shallower than after the earthquake, and concluded that the top of the fluid, which is widely distributed in the lower crust, came up to shallow depths. Those results strongly support the idea that the deeper conductor at depths of $8-10 \mathrm{~km}$ along the $\mathrm{B}^{-\mathrm{B}^{\prime}}$ profile can be connected with free water rather than with the thermal structure. Accordingly, it is believed that the deep conductor found at depths of $8-10 \mathrm{~km}$ along the $\mathrm{B}-\mathrm{B}^{\prime}$ profile is formed by trapped free water dehydrated from a deeper region in this study area. The earthquake swarm activities seem to take place when the trapped free water at depths of 8-10 km comes up to a depth of about $5 \mathrm{~km}$, where the brittle-ductile transition zone exists. In fact, as shown in Fig. 6, no earthquakes took place at depths of 8-10 km.

Another remarkable feature in the resistivity structure shown in Fig. 6 is the low resistive block at a depth of about $3 \mathrm{~km}$. A very small number of earthquakes took place inside block (a) shown in Fig. 8. Most of the earthquakes occurred in the vicinity of block (a). This fact can be explained by the shear strength as it becomes lower, so as not to accumulate large strain because cracks saturated with water in the low resistive block.

\section{Conclusions}

We have discussed the relations among the resistivity structure, the seismic reflectors and activities around the hypocentral area of the 1984 Western Nagano Prefecture earthquake. We summarize the results as follows:

1. The resistivity structure along the A-A' profile indicates a homogeneous structure of high resistivity. Seismicity along the A-A' profile is not so high. Seismic activities, however, can be seen in the boundary between high resistive and relatively lower resistivity regions along this profile.

2. Very low resistivity blocks were found at the shallower and deeper portions on the northwestern side of the model

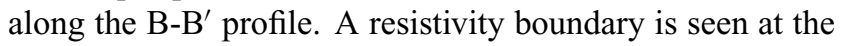

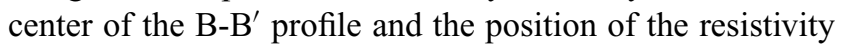
boundary coincides with the location of the earthquake fault of the 1984 Western Nagano Prefecture earthquake. Many earthquakes occurred on the resistivity boundary and above the deeper conductive block. The top layer of the deeper conductive block agrees with the depth of the upper S-wave reflectors. This structure seems to be formed by the free water dehydrated from the magma.

Acknowledgments. We greatly thank the Research Group for Crustal Resistivity Structure in Japan for supplying the MT data in this study field. We are grateful to the officers of Otaki and Mitake village and Agematsu town for their support in our MT surveys, also to the local forest offices of Otaki, Kisofukushima, and Agematsu for permission to set up our MT instruments. The authors express their deep gratitude to Drs. Y. Ogawa and T. Uchida for providing their inversion code for resistivity structure modeling. We thank Drs. T. Goto, S. Sakanaka, and M. Ichiki for their helpful advice. We would like to thank the reviewers, Yuji Mitsuhata and S. G. Gokarn, for their valuable suggestions on an earlier version of the manuscript.

\section{References}

Fuji-ta, K., Y. Ogawa, S. Yamaguchi, and K. Yaskawa, Magnetotelluric imaging of the SW Japan forearc, —a lost paleoland revealed?-, Phys. Earth Planet Inter., 102, 231-238, 1997.

Gamble, T. D., W. M. Goubau, and J. Clarke, Magnetotellurics with a remote magnetic reference, Geophysics, 44, 53-68, 1979.

Geological Survey of Japan, Geological Map of Japan 1:1,000,000, 3rd Edition, CD-ROM Version, Digital Geoscience Map G-1, 1995.

Groom, R. W. and R. C. Bailey, Decomposition of magnetotelluric Impedance tensors in the presence of local three dimensional galvanic distortions, J. Geophys. Res., 94, 1913-1925, 1989.

Gupta, H. K., S. V. V. Sarma, T. Harinarayana, and G. Virupakshi, Fluids below the hypocentral region of Latur earthquake, India; geophysical indicators, Geophys. Res. Lett., 23, 1569-1572, 1996.

Hori, S., H. Aoki, and T. Ooida, Focal mechanisms of the earthquake swarm southeast of Mt. Ontake, Central Honshu, Japan, Zishin, 35, 162-169, 1982 (in Japanese with English abstract).

Horiuchi, S. and The members of the 1986 Joint Seismological Research in Western Nagano Prefecture, Hypocenter locations by a dense network, J. Phys. Earth, 40, 313-326, 1992. 
Iio, Y., R. Ikeda, K. Omura, Y. Matsuda, Y. Shiokawa, M. Takeda, and D. Uehara, Conductivity structure of seismogenic region in the western Nagano prefecture, Butsuri-Tansa, 53, 56-66, 2000

Inamori, T., S. Horiuchi, and A. Hasegawa, Location of mid-crustal reflectors by a reflection method using aftershock waveform data in the focal area of the 1984 Western Nagano Prefecture Earthquake, J. Phys. Earth, 40, 379-393, 1992.

Japan Meteorological Agency, The Western Nagano Prefecture Earthquake, 1984, Report of the Coordinating Committee for Earthquake Prediction, 33, 116-128, 1985.

Kimura, J. and T. Yoshida, Magma transport system beneath Norikura volcanic chains, Gekkan Chikyu (Earth Monthly), 18, 97-103, 1996 (in Japanese).

Miller, C. K. and K. P. Furlong, Thermal-mechanical controls seismicity depth distribution in the San Andreas Fault Zone, Geophys. Res. Lett., 15, 1429-1432, 1988.

Mizoue, M. and Y. Ishiketa, Detection of melting zone beneath fault area of the 1984 Western Nagano Prefecture Earthquake and beneath southeastern foot of Mt. Ontake, Gekkan Chikyu (Earth Monthly), 10, 700-705, 1988 (in Japanese).

Mizoue, M. and I. Nakamura, Mapping of an unusual crustal discontinuity by microearthquake reflections in the earthquake swarm area near Asio, Northwestern Part of Tochigi Prefecture, Central Japan, Bull. Earthq. Res. Inst., Univ. Tokyo, 57, 653-686, 1982.

New Energy and Industrial Technology Development Organization (NEDO), Investigation report of the geothermal development promotion (Otaki area), No. 17, 1988.

Ogawa, Y. and T. Uchida, Two dimensional magnetotelluric inversion assuming Gaussian static shift, Geophys. J. Int., 126, 69-76, 1996.

Ogawa, Y., Y. Honkura, F. Ohtani, H. Kuroki, and Y. Mitsuhata, Preliminary magnetotelluric modeling in the Nikko Volcanic Area-Potential Break of Fluid Trap by Volcanic Intrusion, J. Geomag. Geoelectr., 49, 1073-1078, 1997.

Shichi, R., A. Yamamoto, A. Kimura, and H. Aoki, Gravimetric evidences for active faults around Mt. Ontake, central Japan: Specifically for the hidden faulting of the 1984 Western Nagano Prefecture Earthquake, $J$. Phys. Earth, 40, 459-478, 1992.

Sibson, R. H., Fault zone models, heat flow, and the depth distribution of earthquakes in the continental crust of the United States, Bull. Seism. Soc. Am., 72, 151-163, 1982.

Swift, C. M., A magnetotelluric investigation of an electrical conductivity anomaly in the southern United States, Ph.D. thesis, Dept. of Geol. and Geophy., Mass. Inst. of Technol., Cambridge, 1967.

Takakura, S., M. Takeda, and K. Matsuo, Effects of regional noise on magnetotellurics and their removal by far remote reference method, ButsuriTansa (Geopys. Explor.), 47, 24-35, 1994.

Takeda, J., Y. Iio, Y. Kobayashi, K. Yamamoto, H. Sato, S. Ohmi, H. Ito, R. Ikeda, and E. Yamamoto, The Relationship between seismicity and fluid existing in the crust inferred from $V_{p} / V_{s}$ Ratio, Zisin, 51, 419-430, 1999 (in Japanese with English abstract).

Tanabe, S., Time variation in seismic reflector around Mt. Ontake, M.Sc Thesis, Earth and Planetary Science, Kyoto Univ., 40 pp., 1996.

Ting, S. C. and G. W. Hohmann, Integral equation modeling of three dimensional magnetotelluric response, Geophysics, 46, 192-197, 1981.

Umeda, Y. and K. Ito, A model for the prediction of intraplate large earthquake growing in the inhomogeneous crust, Zisin, 50, 263-272, 1998 (in Japanese with English abstract).

Yamada, N. and T. Kobayashi, Geology of the Ontakesan district. Geological Sheet Map at 1:50,000, Geological. Survey. Japan, 136 p., 1988 (in Japanese with English abstract).

Yamashina, K. and T. Tada, A fault model of the 1984 Western Nagano Prefecture Earthquake based on the distance change, Bull. Earthq. Res. Inst., Univ. Tokyo, 60, 221-230, 1985.

T. Kasaya (e-mail: tkasa@rcep.dpri.kyoto-u.ac.jp), N. Oshiman, N. Sumitomo, M. Uyeshima, Y. Iio, and D. Uehara 